\title{
RESIDENCIAL PORTAL DA PÉROLAII - HABITAÇÃO SOCIALSEGUNDO AS DIRETRIZES DO PROGRAMA MINHA CASA MINHA VIDADA EM BIRIGUI - SP
}

Daiane dos Santos Esquevani', Mayara Pissutti Albano², Sibila Corral de Arêa Leão Honda²,Maria Alessandra Bácaro Boscolli².

${ }^{1}$ Discente do Curso de Arquitetura e Urbanismo da Universidade do Oeste Paulista - UNOESTE. ${ }^{2}$ Docente do Curso de Arquitetura e Urbanismo da Universidade do Oeste Paulista - UNOESTE. E-mail daiane esquevani@hotmail.com

\section{RESUMO}

Esse artigo visa à discussão da habitação social no Brasil, considerando seus aspectos projetuais, discutindo seus reflexos na expansão horizontal e segregação urbanase seus reflexos na qualidade de vida e inserção social de seus moradores. Tem como objeto de estudo o Residencial Portal da Pérola II, implantado na cidade de Biriguí - SP,financiado pela Caixa Econômica Federal através do Programa Minha Casa Minha vida do Governo Federal. Análise pós-ocupacional embasa a pesquisa, cuja metodologia foi de levantamento in loco, através da observação direta. Desta feita, busca-se contribuir para a discussão a aspectos arquitetônicos, urbanos e políticos voltados à habitação de interesse social.

Palavras-chave: Habitação Social, Avaliação Pós- ocupacional, Programa Minha Casa Minha Vida.

\section{INTRODUÇÃO}

Este artigo busca discutir a habitação social executada segundo as diretrizes do Programa Minha Casa Minha Vida do Governo Federal, tendo como objeto de estudo o Residencial Portal da Pérola II, em Birigui, cidade do interior do estado de São Paulo.

O programa Minha Casa Minha Vida foi criado pelo presidente Luís Inácio Lula da Silva em junho de 2009, com o objetivo de atender as necessidadeshabitacionais de famílias de baixa renda, ou seja, famílias que possuam renda mensal de até $\mathrm{R} \$ 1.600,00$ (mil e seiscentos reais), proporcionando assim moradias dignas, com padrões mínimos de sustentabilidade, segurança e habitabilidade (GOVERNO FEDERAL, 2009).

A pesquisa que embasa este artigo buscou compreender as diretrizes do Programa Minha Casa Minha vida do Governo Federale o modo como vem sendo executado os conjunto habitacionais inseridos através deste programa, a partir do objeto de estudo supracitado.

\section{OBJETIVOS}

O objetivo desta pesquisa foi levantar a inserção do Programa Minha Casa Minha Vida na cidade de Birigui - SP. Possui como foco de estudo o Residencial Portal da Pérola II, e visa investigar as características das unidades habitacionais e aspectos de conforto ambiental que 
possam interferir na qualidade de vida de seus moradores, bem como questões ligadas a segregação socioespacial e expansão urbana.

\section{METODOLOGIA}

A metodologia seguida foi baseada em pesquisas bibliográficas, documentais e de campo. O levantamento bibliográfico está baseado em conceitos sobre expansão e segregação urbana, habitação social, políticas públicas de habitação. As pesquisas de campo incluíram levantamentos de dados sobre a implantação e observação e levantamentos métricos das unidades habitacionais.

\section{DISCUSSÃO}

Os problemas relativos à habitação no Brasil constituem um fato, originado em tempos remotos, porém, a atuação governamental referente à habitação é recente, e coincide com o processo de industrialização dos centros urbanos (HONDA, 2011). Sempre existiram moradias precárias, mas estas só passaram a ser notadas, em meados da década de 1890, quando se tornaram uma ameaça à saúde pública (LEAL, 1990).

O processo de urbanização no Brasil, que historicamente têm-seacentuada elitização da distribuição de terras, as omissões e descasos nas políticas públicas, provocaram uma série de déficits ao acesso a moradia e carência de infraestrutura de saneamento básico, e de políticas urbanas habitacionais, que acarretam na diminuição da qualidade de vida nos centros urbanos. (LORENZETTI, 2001)

Diante do processo de crise urbana, para o enfrentamento destes problemas,são necessárias formulações de políticas públicas coerentes aos cidadãos que vivem no meio urbano, em especial as relativas ao uso do solo urbano, à habitação, à infraestrutura de saneamento básico e de transportes, ao meio ambiente, etc., a fim de se construir ambientes urbanos justos e equilibrados (ANTONUCCI, 2009).

Segundo Romero (2011), desde o período do pós-guerra os conjuntos habitacionais não satisfaziam as exigências dos moradores, e diversos programas e políticas públicas já foram criadas na tentativa de mitigar os problemas e déficits relativos à habitação, tal como o Programa Minha casa Minha Vida do Governo Federal, criado no ano de 2009 no governo do então presidente Luiz Inácio Lula da Silva, como o objetivo de atender as necessidades de habitação da população de baixa renda. 
Os empreendimentos vinculados a este programa são executados com parcerias entre Estado, Municìio, Entidades Privadas e a Caixa, que é responsável pela venda das unidades às famílias beneficiadas.

Entre as diretrizes do Programa estão a exigência de o empreendimento ser inserido na malha urbana, possuir infraestrutura básica previamente, que permita as ligações de água, esgotamento sanitário, energia elétrica, transporte público. Os empreendimentos devem ter até 500 unidades nos casos de loteamentos e até 250 unidades quando condomínios fechados (GOVERNO FEDERAL, 2009).

Segundo o Programa Minha Casa Minha Vida, as unidades habitacionais dever possuir pelo menos $42 \mathrm{~m}^{2}$ de área construída em unidades do tipo apartamento, e no mínimo $38 \mathrm{~m}^{2}$ de área construída para casas.

A seguir, será analisado o Residencial Portal da Pérola II, implantado na cidade de Birigui SP, avaliando as características construtivas das unidades, a fim de discutir a qualidade das habitações implantadas através deste Programa do Governo Federal.

\subsection{Residencial Portal da Pérola II}

O Residencial Portal da Pérola II está localizado na cidade de Birigui - SP, e foi financiadopelo programa Minha Casa Minha Vida, do Governo Federal. O terreno onde foi inserido situa-se a mais de $5 \mathrm{~km}$ do centro da cidade, conforme pode ser observado na Figura 1, não havendo muitos comércios que atendam o local nem serviços como escolas, postos de saúde e o transporte público escasso. Localiza-se em uma área não contígua à malha urbana consolidada, configurando assim, um caso de exclusão socioespacial e reforçando a expansão horizontal da malha urbana. 


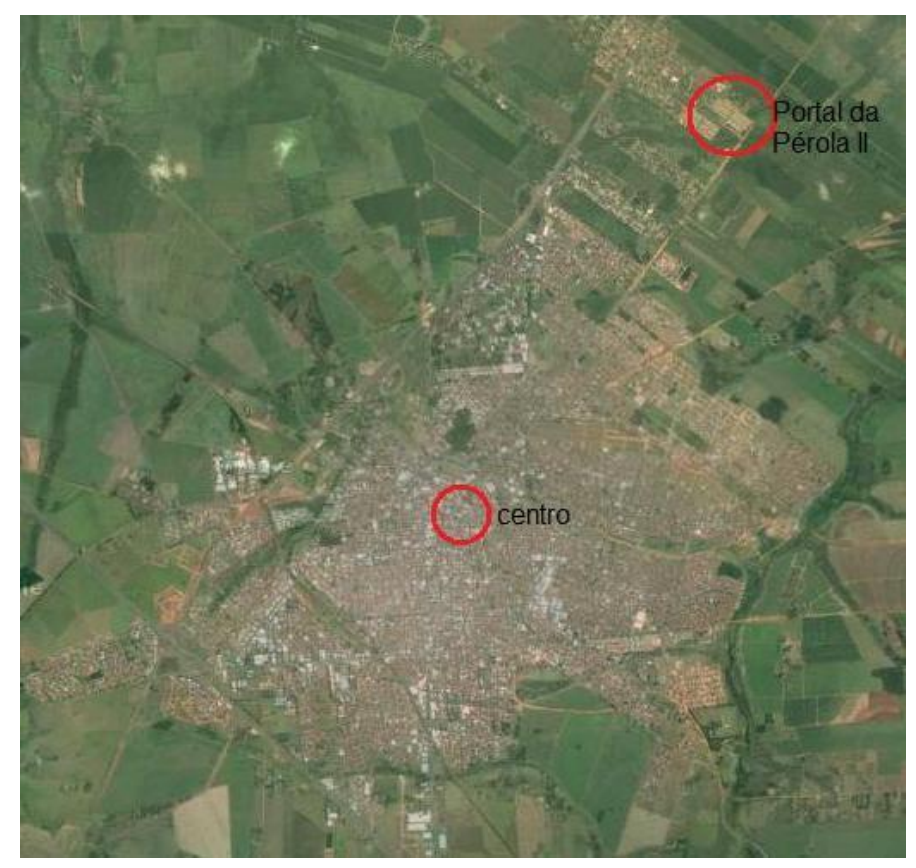

Figura 1.-Foto aérea da cidade de Birigui, e localização do centro e conjunto habitacional Fonte:Gogle Earth, organização: Daiane Esquevani, 2013.

\subsection{Avaliação Pós-ocupacional da habitação social}

Durante as pesquisas, foi analisa uma residência do conjunto habitacional, onde reside uma senhora de 67 anos.

A unidade habitacional possui $37,52 \mathrm{~m}^{2}$, contendo dois dormitórios, uma cozinha, um banheiro e uma sala, conforme pode-se verificar na Figura2. Ao caminhar pela residência é possível notar claramente, a dificuldade de deslocamento sem esbarrar em algum móvel, já que os cômodos possuem dimensões resumidas, dificultando a organização da mobília da residente.

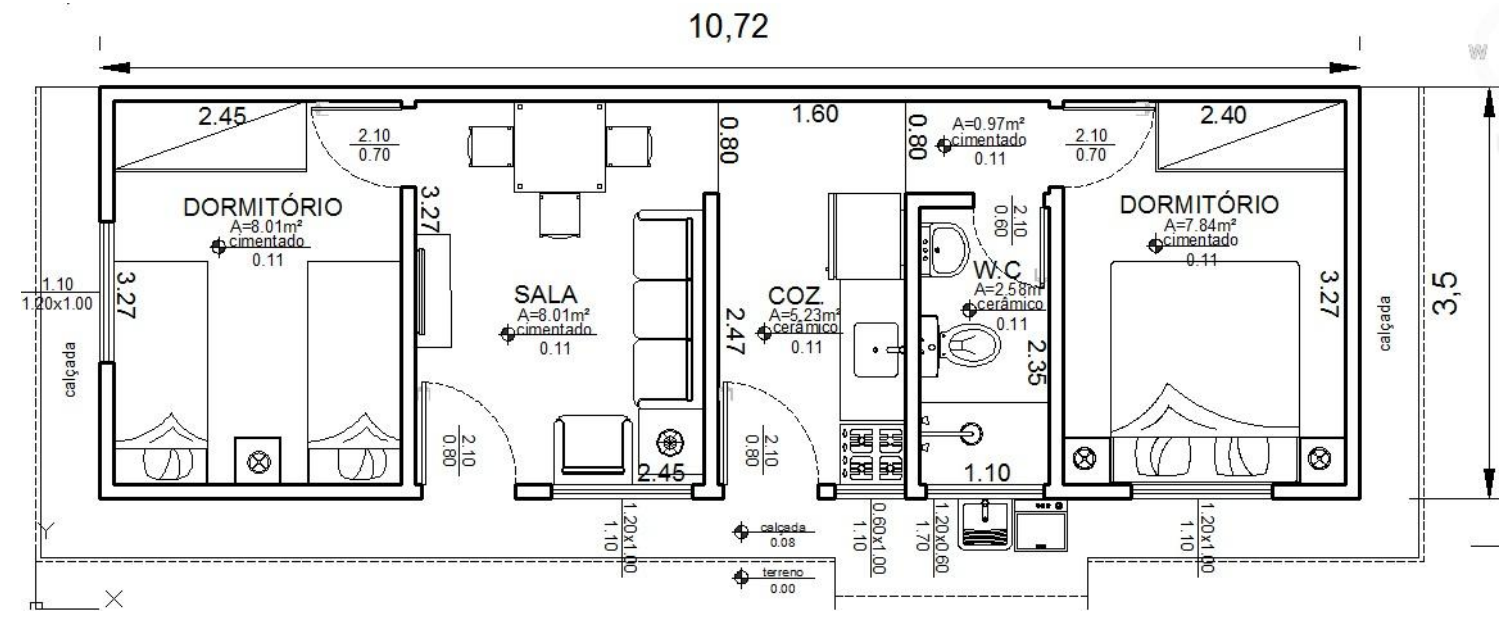

Figura 2. Planta baixa das unidades habitacionais do conjunto habitacional Portal da Pérola II Fonte: Matheus Vitorelli, engenheiro responsável pelas construções. 
Segundo as especificações mínimas da Caixa, o pisto das unidades habitacionais deveriam ter acabamento de cerâmica esmaltada com rodapé em toda unidade, porém foi constatado que esta diretriz não foi cumprida, visto que as residências deste conjunto habitacional foram entregues aos beneficiários com revestimento cerâmico apenas no piso do banheiro e cozinha, o restante dos cômodos sem acabamento, foram entregues no contra piso. Este fato dificulta a limpeza e manutenção da higiene nas residências, além da possibilidade de ferimentos caso um morador venha cair no interior da casa.

O Programa Minha Casa Minha Vida não estabelece uma área mínima para os cômodos das residências, apenas estipula o mobiliário que deve conter em cada ambiente, deixando sob a responsabilidade do projetista, a formatação dos ambientes segundo o mobiliário previsto, a fim de evitar divergências com as legislações estaduais ou municipais que versam sobre as dimensões mínimas de cada ambiente. Porém, o Programa Minha Casa Minha Vida, juntamente com o Fundo de Arrecadamento Residencial (FAR), estabelecem parâmetros para garantir um padrão mínimo de qualidade às unidades habitacionais (ver Tabela 1). Nesta tabela há uma determinação de dimensões mínimas para dada tipo de ambiente. Por exemplo, em cômodos como, cozinha, sala e banheiro, são estipulados largura mínima de 1,80m, 2,40m, 1,50m, respectivamente, pela tabela, e que não são obedecidos pelo projeto destas unidades. 
Tabela 1. Especificações mínimas para casas do Fundo de Arrecadamento Residencial (FAR).

\begin{tabular}{|c|c|}
\hline Dormitório casal & $\begin{array}{l}\text { Quantidade mínima de móveis: } 1 \text { cama }(1,40 \mathrm{~m} \text { x1,90m); } 1 \text { criado-mudo } \\
(0,50 \mathrm{~m} \\
\text { x 0,50m); } 1 \text { guarda roupa }(1,60 \mathrm{~m} \times 0,50 \mathrm{~m}) \text {. Circulação mínima entre } \\
\text { mobiliário } \\
\text { e/ou paredes de } 0,50 \mathrm{~m} \text {. }\end{array}$ \\
\hline Dormitório 2 pessoas & $\begin{array}{l}\text { Quantidade mínima de móveis: } 2 \text { camas }(0,80 \mathrm{~m} \times 1,90 \mathrm{~m}) ; 1 \text { criado- } \\
\text { mudo }(0,50 \mathrm{~m} \\
\times 0,50 \mathrm{~m}) ; 1 \text { guarda roupa }(1,50 \mathrm{~m} \times 0,50 \mathrm{~m}) \text {. Circulação mínima entre as } \\
\text { camas } \\
\text { de } 0,80 \mathrm{~m} \text {. Demais circulações mínimo de } 0,50 \mathrm{~m} \text {. }\end{array}$ \\
\hline Cozinha & $\begin{array}{l}\text { Largura mínima da cozinha: } 1,80 \mathrm{~m} \text {. Quantidade mínima: } 1 \text { pia }(1,20 \mathrm{~m} \times \\
0,50 \mathrm{~m}) \text {; } \\
\text { Fogão }(0,55 \mathrm{~m} \times 0,60) \text {; e geladeira }(0,70 \mathrm{~m} \times 0,70 \mathrm{~m}) \text {. Previsão de armário } \\
\text { sob a } \\
\text { pia e gabinete. }\end{array}$ \\
\hline $\begin{array}{l}\text { Sala de estar / } \\
\text { refeições }\end{array}$ & $\begin{array}{l}\text { Largura mínima sala de estar/refeições: } 2,40 \mathrm{~m} \text {. Quantidade mínima de } \\
\text { móveis: } \\
\text { sofás com número de assentos igual ao número de leitos, mesa para } 4 \\
\text { pesso- } \\
\text { as; e estante/armário para TV. }\end{array}$ \\
\hline Banheiro & $\begin{array}{l}\text { Largura mínima do banheiro: } 1,50 \mathrm{~m} \text {. Quantidade mínima: } 1 \text { lavatório } \\
\text { sem coluna } \\
1 \text { vaso sanitário com caixa de descarga acoplada, } 1 \text { box com ponto para } \\
\text { chu - } \\
\text { Veiro }(0,90 \mathrm{~m} \times 0,95 \mathrm{~m}) \text { com previsão de instalação de barras de apoio e } \\
\text { banco } \\
\text { articulado, desnível máx. } 15 \mathrm{~mm} \text {; assegurar a área para transferência ao } \\
\text { vaso } \\
\text { sanitário e ao box. }\end{array}$ \\
\hline Área de Serviço & $\begin{array}{l}\text { Quantidade mínima: } 1 \text { tanque }(0,52 \mathrm{~m} \times 0,53 \mathrm{~m}) \text { e uma máquina }(0,60 \mathrm{~m} \\
\times 0,65 \mathrm{~m})\end{array}$ \\
\hline
\end{tabular}

Fonte: Caixa Econômica Federal; disponível em:

http://downloads.caixa.gov.br/ arquivos/habita/mcmv/Especificacoes Casa MCMV2.pdf. Acesso em: 20.04.2013.

Desta feita, observa-se a divergência entre a regulamentação e a realidade, comparando os dados da Tabela 1 e da Figura 2, vê-se que na unidade habitacional a largura da cozinha é de 1,60m e o mínimo exigido é de 1,80m; no banheiro a largura é de 1,10 enquanto deveria ser de no mínimo 1,50m. As Figuras 3 e 4 ilustram a situação supracitada, onde é possível notar o racionamento dos espaços. 


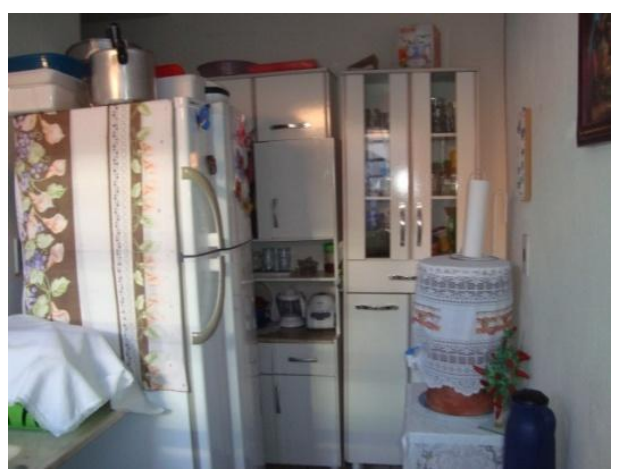

Figura 3. Cozinha da residência

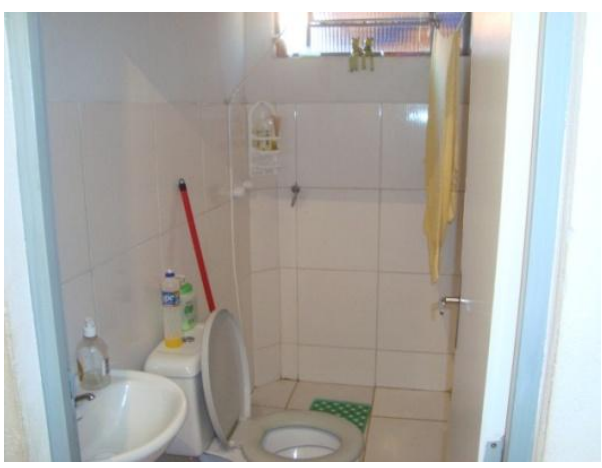

Figura 4:.Banheiro da residência

Fonte: Daiane Esquevani, 2013

A solução projetual adotada neste conjunto habitacional, compromete o conforto dos moradores visto que não há uma setorização dos usos no interior da residência, ou seja, os dois dormitórios encontram-se em lados opostos, sendo que um deles distante do banheiro e muito próximo à área social (sala) da casa. A redução excessiva das dimensões dificulta o fluxo, visto que no layout estabelecido (vide Figura 2) a mesa para refeições interrompe a circulação entre a sala e um dos dormitórios.

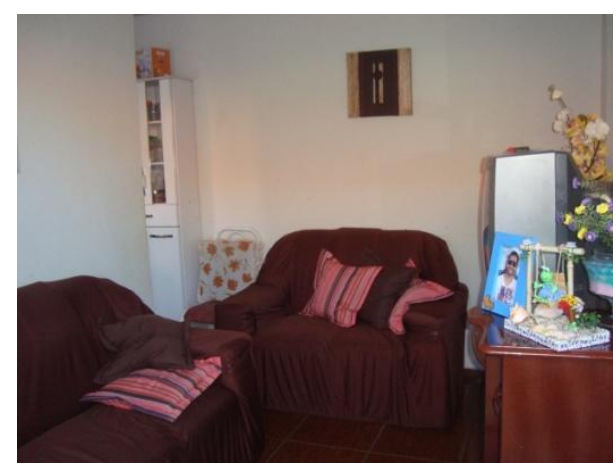

Figura 5. sala da residência com

disposição dos móveis comprometendo a circulação.

Fonte: Daiane Esquevani, 2013

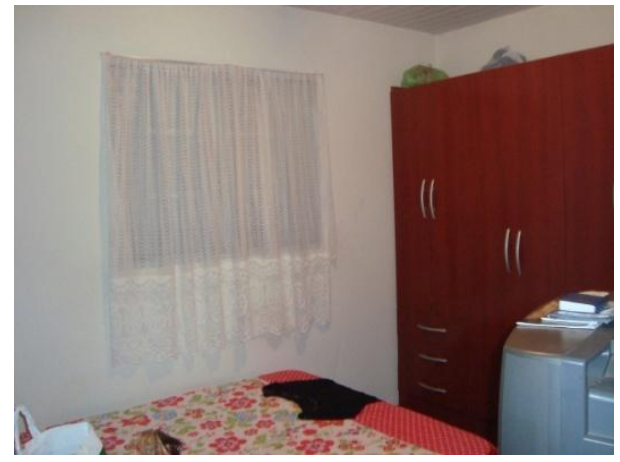

Figura 6. dormitório da residência.

Fonte: Daiane Esquevani, 2013

Comparando o layout e a Tabela de Especificações Mínimas do programa Minha Casa Minha Vida (FAR) onde há as medidas mínimas dos mobiliários (vide Tabela 1), é possível constatar que as dimensões dos mobiliários também foram alteradas. As camas de solteiro, por exemplo, estão medindo na planta de layout, $(0.80 \mathrm{~m} \times 1,80 \mathrm{~m})$ sendo que o correto seria de $(0,80 \mathrm{~m} \times$ $1,90 \mathrm{~m}$ ), foram diminuídos $0.10 \mathrm{~cm}$ em seu comprimento. Isso também foi feito com a cama de casal, assim, quando os móveis comprados em lojas são inseridos nas residências ela se torna mais 
apertada e com o fluxo mais comprometido do que a situação que consta no projeto, (vide Figura 5) .

A casa é geminada, e não houve nenhuma preocupação com a acústica, desta feita, podese ouvir todos osbarulhos e conversas da casa vizinha. A fachada principal possui a janela de um dos dormitórios, não constando nenhuma preocupação estética,conforme ilustra as Figuras 5 e 6. O muro de divisa das casas fica sob responsabilidade dos moradores construírem, sendo assim muitas famílias precisam aprender a conviver com menos privacidade, pelo fato de não terem condições financeiras para a construção deste.

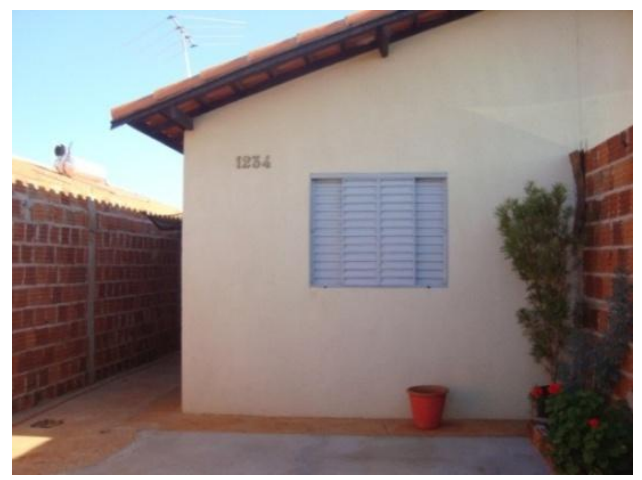

Figura 7. Fachada da casa.

Fonte: Daiane Esquevani, 2013

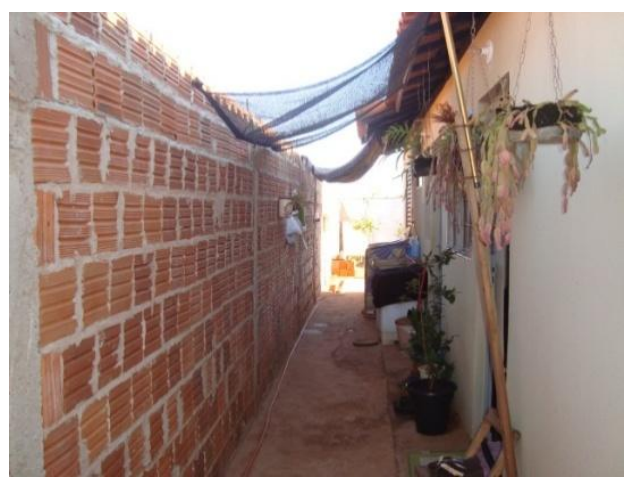

Figura 8. Corredor lateral da residência

Fonte: Daiane Esquevani, 2013

\section{CONSIDERAÇÕES}

Considerando o Residencial Portal da Pérola II, habitação social em Birigui - SP, foco deste estudo, cujo financiamento se deu através do Governo Federal, por meio do Programa Minha Casa Minha Vida, verifica-se que ocorre falta de controle na execução e aprovação dos projetos das unidades residenciais, visto que descumprem as exigências do programa quando ao dimensionamento dos ambientes e ao acabamento das unidades.

As características construtivas do empreendimento proporcionam problemas ambientais internos às unidades residenciais, prejudicando a qualidade de vida dos beneficiados. A relação do empreendimento com o espaço urbano dificulta questões de acessibilidade e mobilidade, pois, se encontra fora da malha urbana consolidada.

Pesquisar e compreender os problemas e virtudes, erros e acertos, verificar as decisões projetuais, são fundamentais para melhorar a qualidade das habitações populares propostas no Brasil, assim como possibilitam a elaboração de políticas habitacionais mais inclusivas e mais adequadas às realidades ambiental e social locais. 


\section{REFERÊNCIAS}

ANTONUCCI, Denise. ONU e 30 anos do Un-Habitat. São Paulo, 5o Fórum de Pesquisa FAU Mackenzie, 2009.

GOVERNO FEDERAL - Manual do Beneficiário do Programa Minha Casa, Minha Vida - Entidades, 2009.Disponível em: http://www.unmp.org.br/index.php?option=com content\&view=article\&id=277:a-resolucao-do-novo-credito-solidario-saiu\&catid=64: $\quad$ creditosolidario\&Itemid=98Acesso em: 02/04/13.

HONDA, Sibila C.A.L. Habitação de Baixa Renda como Produto do Capital - o Programa de Arrendamento Residencial (PAR) em Presidente Prudente. São Paulo: FAU/UPM, 2011. Tese (Doutorado).

LEAL, Edson. P. B. Evolução urbana e a questão da habitação no Brasil: 1964 - 1988. Assis - SP, 1990 (Dissertação de Mestrado).

LORENZETTI, Maria Sílvia B. A questão habitacional no Brasil. Brasília: Consultoria Legislativa da Câmara dos Deputados, junho/2001(Relatório). Disponível em: http://bd.camara.gov.br/bd/bitstream/handle/bdcamara/1469/questao ha

bitacional lorenzetti.pdf?sequence=1, Acesso em: 17 .ago. 2010 